This item was submitted to Loughborough's Research Repository by the author.

Items in Figshare are protected by copyright, with all rights reserved, unless otherwise indicated.

\title{
Thermal boundary layer modelling in 'motored' spark ignition engines
}

PLEASE CITE THE PUBLISHED VERSION

PUBLISHER

(c) Society of Automotive Engineers

VERSION

VoR (Version of Record)

LICENCE

CC BY-NC-ND 4.0

\section{REPOSITORY RECORD}

Jenkin, R.J., E.H. James, and W. Malalasekera. 2019. "Thermal Boundary Layer Modelling in 'motored' Spark Ignition Engines”. figshare. https://hdl.handle.net/2134/5714. 
This item was submitted to Loughborough's Institutional Repository (https://dspace.lboro.ac.uk/) by the author and is made available under the following Creative Commons Licence conditions.

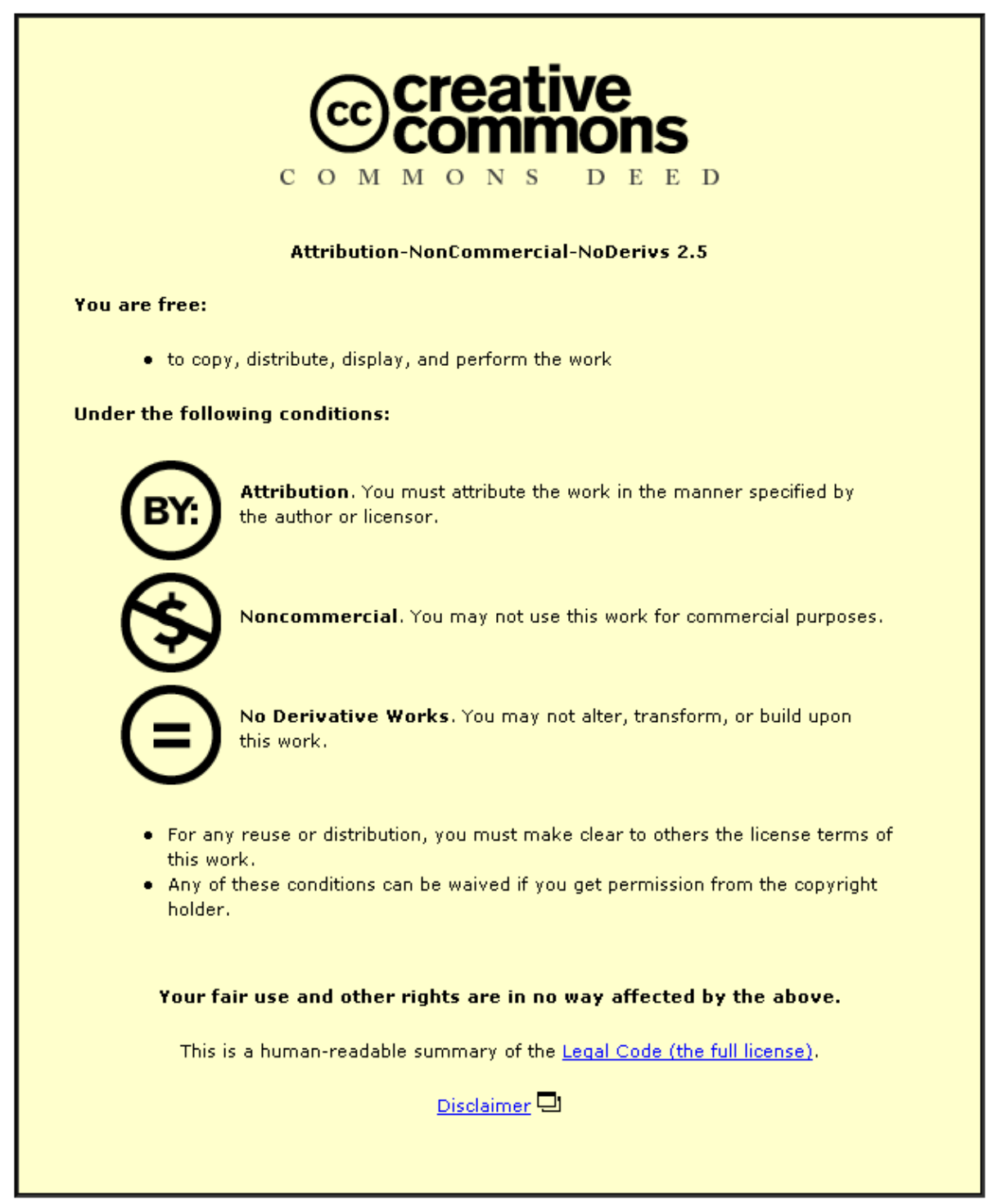

For the full text of this licence, please go to: http://creativecommons.org/licenses/by-nc-nd/2.5/ 


\section{Thermal Boundary Layer Modelling in 'Motored' Spark Ignition Engines}

R. J. Jenkin, E. H. James, and W. Malalasekera

Loughborough Univ.

Reprinted from: Diagnostics and Modeling in SI Engines

(SP-1212)

The Engineering Society

For Advancing Mobility

Land Sea Air and Space.
International Fall Fuels \& Lubricants Meeting \& Exposition San Antonio, Texas October 14-17, 1996 


\title{
Thermal Boundary Layer Modelling in 'Motored' Spark Ignition Engines
}

\author{
R. J. Jenkin, E. H. James, and W. Malalasekera \\ Loughborough Univ.
}

Copyright 1996 Society of Automotive Engineers, Inc.

\begin{abstract}
A newly developed piece-wise method for calculating the effects of near-wall turbulence on the transport of enthalpy and hence the thermal boundary layer temperature profile in "motored" spark ignition engines has been compared with methods that have previously been employed in the development of expressions for the gas-wall interface heat flux. Near-wall temperature profiles resulting from the inclusion of the respective expressions in a "quasi-dimensional" thermodynamic engine simulation have been compared and in one case show considerable differences throughout the compression and expansion strokes of the "motored" engine cycle. However, the corresponding heat fluxes calculated from the simulated temperature profiles all show good agreement with measured results. It is postulated that gas-wall interface heat flux is largely controlled by the boundary layer behaviour close to the combustion chamber surfaces and the temperature profile in the outer regions of the boundary layer has considerably less influence. Comparisons have also been made between measured TDC near-wall temperature data (expressed in dimensionless form) and the wall function approach when modified for use in the cylinders of reciprocating engines. The high swirl case shows good agreement with the wall functions, but the low swirl case does not. This is attributed to the changing nature of the hydrodynamic boundary layer in the two instances with the low swirl case being more consistent with laminar behaviour. Engine simulations incorporating the new method for the evaluation of near-wall turbulence effects have been used to demonstrate the thermal boundary layer behaviour throughout the compression and expansion strokes of a "motored" cycle. Piston induced work effects are observed to have a significant influence.
\end{abstract}

\section{INTRODUCTION}

Thermal [1],[2],[3] and momentum [4],[5],[6] boundary layers have been proven to exist at the gas-wall interfaces of internal combustion engines. Recently, much research has been directed towards the empirical examination of these in-cylinder boundary layers $[4],[5],[6],[7]$ and the subsequent modelling of the physical phenomena responsible for their development $[8],[9],[10],[11],[12],[16]$. Data concerning the nature of boundary layers in the cylinders of reciprocating engines has proven to be difficult to acquire due to problems associated with experimental access coupled with the generally hostile environment. As a result, the formulation and validation of models specifically for engine boundary layers is difficult. To overcome this, many studies have drawn the analogy between in-cylinder boundary layers and those found in fully developed, turbulent flows adjacent to flat plates and in pipes for which much empirical data and many well proven models exist.

Thermal boundary layer modelling techniques fall into two categories:

i) wall functions where algebraic expressions are used to describe dimensionless temperature profiles. These are universally applicable to fully developed, turbulent boundary layers adjacent to tlat plates [10],[11],

ii) models which directly account for the physical processes within the boundary layer. The Conservation of Enthalpy Equation is applied to the boundary layer region which either can be numerically solved to give temperature distributions [8],[9] or integrated throughout to give expressions for heat thux $[13],[14],[15]$. The effects of turbulence on the transport of enthalpy are accounted for by using algebraic expressions for the near-wall distribution of $\mu_{t} / \mu$ and $k_{t} / k$ or from the use of two equation turbulence models in which the turbulent kinetic 
energy, $k$, and its dissipation, $\varepsilon$, are considered to be conserved properties and form two extra transport equations from which local turbulence effects can be estimated.

The latter modelling technique is preferable because the physical processes controlling thermal boundary layer behaviour are directly accounted for. However, the simulation of in-cylinder boundary layers by direct numerical solution of the relevant conservation equations is complicated by the scale of the boundary layer in comparison to the overall domain size i.e. the cylinder. To enable sufficient resolution for accurate simulations of the boundary layer region, extremely small mesh sizes are required necessitating computations beyond the scope of current computer technology. Jennings and Morel [9] have overcome this by using a separate one-dimensional mesh in the boundary layer which is coupled with a conventional mesh for the simulation of the cylinder bulk gases. Most commonly however, wall functions are employed in multi-dimensional codes to model the temperature distribution in the boundary layer. The success of the wall function method for evaluating boundary layer temperature profiles in the cylinders of internal combustion engines is dependent on there being physical similarity between the turbulence behaviour in these boundary layers and those in fully developed, turbulent flows adjacent to flat plates/ducts on which the wall function method is based. Alternatively, the accuracy of the direct simulation of boundary layer temperature profiles is dependent on the method employed to account for turbulent eddy transport effects.

This paper is concerned with the latter approach to the simulation of the thermal boundary layer and utilises a thermodynamic "quasi-dimensional" model of the compression and expansion strokes in a "motored" engine to facilitate predictions [16]. In this context, near-wall temperature profiles obtained from existing algebraic expressions for $k_{t} / k$ are compared with those using a new empirically based $k_{t} / k$ calculation method outlined previously $\{16\}$. Predictions in all cases are validated against measured results [2]. The applicability of the use of such expressions is discussed as is the validity of the Law of the Wall to engine-type flows. The thermal boundary layer variation during compression and expansion is examined as are the effects of wall temperature and piston-induced pressure work on the temperature profiles in the thermal boundary layer.

\section{ALGEBRAIC EXPRESSIONS FOR NEAR-WALL TURBULENCE EFFECTS}

A "quasi-dimensional" model simulating the compression and expansion processes in a "motored" I.C engine has been modified to resolve the near-wall temperature gradients. Details of the mathematical routines and the modifications made to achieve this have been discussed in detail elsewhere [16]. Essentially however, the model combines a one-dimensional form of the Conservation of Enthalpy Equation applied to the boundary layer region with a thermodynamic engine simulation enabling accurate predictions of the incylinder, near-wall temperature field with minimal computational effort. The one-dimensional Conservation of Enthalpy Equation is employed in the form:

$$
\frac{\partial(\rho h)}{\partial t}=\frac{\partial}{\partial x}\left(\left[k_{3}+k\right] \frac{\partial T}{\partial x}\right)+\frac{d P}{d t}+S_{h}
$$

Bulk convection effects have been neglected and enthalpy transport due to turbulent velocity fluctuations are accounted for within the diffusion term by the inclusion of the effective eddy thermal conductivity $k_{t}$. A sub-model computes a ratio for $k_{t} / k$ and several expressions have been used for comparative purposes in this connection.

One such method has been developed from an analysis of empirical near-wall turbulence intensity data and has been described by Jenkin et al [16]. This approach is not strictly a turbulence model but accounts for the effects of observed near-wall turbulence on the transport of enthalpy in the thermal boundary layer. Turbulent-eddy enthalpy transport is assumed to be negligible in the laminar sublayer and to increase linearly across a thickness corresponding to the region where normal turbulence intensity increases [4] until a maximum constant value is attained in the core bulk gases. Here, turbulence is assumed to be approximately homogenous and isotropic [20]. The type of $k_{t} / k$ variation that ensues is shown in Figure 3. This approach has been validated [16] from comparisons of predicted TDC temperature profiles with those measured under both high and low swirl conditions in a modified "motored" research engine [2]. Two alternative expressions for turbulent eddy transport effects in boundary layers are also examined in this paper. These are due to Dao et al [17] and Yang and Martin [13]. Dao et als' expression is a function of position relative to the cylinder head. It was derived using turbulent pipe flow skin friction theory where the Reynolds Number was calculated by relating mean piston speed to clearance volume and it assumes that the boundary layer space dependent eddy thermal conductivity, $K_{1}^{\prime}$, can be approximated using a $1 / 7$ th power law. The resultant equation is:

$$
\begin{aligned}
\frac{K_{i}^{\prime}}{k} & =a\left(\frac{P_{I}}{P_{a}} \frac{c^{2} \omega}{v_{w}} \frac{T_{w^{\prime}}}{T_{1}} \frac{r}{c} S R \times C R\right)^{0.75} \\
& \times\left(\frac{T_{w^{\prime}}}{T_{k}}\right)^{0.58}\left(\frac{s}{c}\right)^{1 / 7} y^{1 / 7}
\end{aligned}
$$

and has been incorporated in this form into the engine simulation to compute $k_{l} / k\left(k_{t}=K_{t}^{\prime}\right)$. Yang and Martin's expression is 


$$
\frac{\mu_{i}}{\mu}=\kappa y^{+}\left[1-\exp \left(-2 b \kappa y^{+}\right)\right]
$$

and provides a good fit to the $\mu_{l} / \mu$ expressions developed by Mellor [18] and Reichardt [19]. $k_{f} / k$ is obtained using the equation:

$$
\frac{k_{f}}{k}=\frac{\mu_{i}}{\mu} \frac{\operatorname{Pr}}{\operatorname{Pr}_{f}}
$$

where $\operatorname{Pr} / \mathrm{Pr}_{t}$ is assumed to equal 0.72 throughout the boundary layer. This ratio is known to vary in the inner region of the boundary layer [46] but the value used represents a reasonable average.

Heat fluxes calculated from the predicted temperature profiles for the three $k_{t} / k$ expressions mentioned above are compared with the measured results of Yang and Martin [13] obtained in a "motored" engine under the conditions presented in Table 1. After a parametric study into the effects of the computational grid on the accuracy of the calculated temperature profiles, a grid of 20 nodes was chosen for all the calculations enabling sufficient resolution of the predicted boundary layer temperature profiles with the minimum of computer processing time. The grid is weighted towards the cylinder walls so that there are usually five nodes within the laminar sub-layer. A measure of the global in-cylinder turbulence level is required as empirical input for the three boundary layer

Table 1: Engine operating conditions (Yang and Martin [13]).

Compression Ratio 11

Inlet Charge Temperature (K)

Inlet Manifold Pressure (kPa).

Crankshaft Speed (r.p.m).

Average Wall Temperature (K)

Steady State Max Swirl Ratio

$P_{M A X}-P_{M I N} \quad(\mathrm{kPa})$

Table 2: Empirical Input Used in the Calculation of Heat Fluxes and Simulated Temperature Profiles.

\section{Jenkin et al [16]:}

Core turbulent eddy transport ratio. $\left(k_{t} / k\right) \quad 70$

Extent of wall effects into core turbulence, 1.1

$d(\mathrm{~mm})$

Laminar sub-layer thickness ( $\mathrm{mm}$ )

No. of boundary layer model elements.

Dao et al [17]:

Swirl Ratio. (SR)

No. of boundary layer model elements.

Yang and Martin [13]:

Cyclicly Averaged Global Friction

Velocity, $u^{*}(\mathrm{~m} / \mathrm{s})$

No. of boundary layer model elements. models (see Table 2). Jenkin et al's model requires the specification of a value for the bulk gas ratio of $k_{l} / k$ whereas Dao et al's expression needs the swirl ratio, SR. Yang and Martin use the friction velocity $u^{*}$. It is important that there is consistency between the values chosen for the adjustable constants in the three expressions. The following section outlines a basic analysis to validate the respective values chosen and shows that the required consistency is achieved.

The heat fluxes measured by Yang and Martin [13] were obtained in a pancake-shaped combustion chamber with a shrouded inlet valve. They have quoted a maximum measured steady state swirl ratio of 7.15 but it is likely that this value will be significantly less for the low engine speed in the case studied here (see Table 1). A further decline in the IVC swirl ratio of between $30 \%$ to $45 \%$ can be expected during the compression stroke [30],[32],[38],[39]. Thus, the value of 2.0 used in Dao et al's expression is reasonable for the operating conditions simulated. This swirl ratio can be related to the friction velocity, $u^{*}$, employed in Yang and Martin's expression [13] by the equation

$$
u^{*}=\sqrt{\tau_{w / \rho}}
$$

The wall shear stress can be calculated by utilising the observation that the flow field can be expected to approximate solid body rotation at TDC [30],[20]. For solid body rotation, Hill and Zhang [30] define the Friction Coefficient, $C_{f 0}$, at radius, $r$, on the cylinder head and piston crown as

$$
C_{f 0}=\frac{\tau_{w}}{\left(1 / 2 \rho \omega^{2} r^{2}\right)}
$$

whilst the curved liner surface Friction Coefficient, $C_{f s}$, for a cylinder of radius $R$ is

$$
C_{f s}=\frac{\tau_{w}}{\left(1 / 2 \rho \omega^{2} R^{2}\right)}
$$

They subsequently assume that $C_{f}=C_{f 0}=C_{f s}$ so that

$$
\frac{\tau_{w}}{\rho}=C_{f}\left(1 / 2 \omega_{s}{ }^{2} R^{2}\right)
$$

The Friction Coefficient in this expression was obtained from Heywood [34] (based on flat plate Reynolds Number theory) and is of the form

$$
C_{f}=0.037 \lambda\left(\operatorname{Re}_{B}\right)^{-0.2}
$$

where $\lambda$ is a constant to account for curvature effects $(\lambda=1.5$ [34] $)$ and $\operatorname{Re}_{B}=\left(B \omega_{s} / 2\right)(\pi B) \rho / v$. The Reynolds Number is a function of the inverse of the dynamic viscosity which varies during compression. Yang and Martin [13] have related the mean swirl velocity to the engine speed to obtain a global expression for $u^{*}$ which remains constant throughout the compression and expansion strokes and over the entire cylinder surface. Thus, the viscosity is estimated using the average cylinder 
pressure and temperature throughout compression and expansion in order to compute a cyclically averaged global value for $u^{*}$. This enables a direct comparison to be made between the computed value for $u^{*}$ and that used in the calculation of $y^{+}$in Yang and Martin's expression (EQ (3)) [13]. A value for $v$ of $3.8 \mathrm{e}-6 \mathrm{~m}^{2} / \mathrm{s}$ gives a cyclically-averaged global friction coefficient, $C_{\text {fAV }}$, of

0.005 . This is similar to the upper values of Friction Coefficient calculated by Hill and Zhang [30] in their numerical analysis of swirl flow in a constant volume combustion chamber and was thus used in EQ (8) to give $\tau_{w} / \rho . u^{*}$ is calculated using EQ (5) to be 0.256 which shows good agreement with the value of 0.268 used both by Yang and Martin [13] and us in this work. It represents the cyclically averaged, global value for $u^{*}$ and is consequently an approximate method for quantifying the in-cylinder fluid motion. The swirl ratio is also a fundamental parameter in the calculation of $\mathrm{Re}_{\mathrm{B}}$. The value of 2 used to account for in-cylinder fluid motion in Dao et al's expression (see Table 2) was also employed in the calculation of $\tau_{w} / \rho$ to generate the empirical input into Yang and Martin's expression in order to effect a uniformity of approach between the two expressions.

To validate the core value of $k_{f} / k$ used in the newly developed expression (Table 2), use has been made of the commonly accepted belief that TDC turbulence intensity, $u^{\prime}$, in a pancake shaped combustion chamber with swirl at low engine speeds can be approximated as approximately half the mean piston speed, $\bar{V}_{P}$. [33], [30]. Thus, the mean turbulence kinetic energy, $k$, in the bulk cylinder gases is related to the turbulence intensity by the equation:

$$
k=\frac{3}{2} u^{\prime 2}
$$

and, if the large eddy length scale, $l$, is known, the turbulent eddy viscosity, $v_{f}$, can be calculated using the expression:

$$
v_{1}=C_{D} \sqrt{k} l
$$

where, $C_{D}$, is a universal constant defined as 0.09 [35]. If the integral length scale is assumed to be representative of the lower limit of the large eddy length scale, Fraser and Bracco's integral length scale measurements [31] can be used to provide a value of $3 \mathrm{~mm}$ for $l$ in $\mathrm{EQ}(11)$. With a knowledge of the mean piston speed, EQ (10) and EQ (II) then evaluate $v$, which, in this case, is approximately $2.5 \mathrm{E}-4 \mathrm{~m}^{2} / \mathrm{s}$. Substitution into EQ.4 hence reveals a resultant value for $k_{t} / k$ of 64 which compares well with the value of 70 used in this study. This appears acceptable given the simplicity of the approach to such validation.

As a result of the work described in this section, the empirical input between the three models has achieved a degree of consistency which is essential in order to accurately correlate predictions between the models. The specified $k_{t} / k$ and bulk average $u^{*}$ values are reasonable for flow in a pancake shaped combustion chamber under "motored" conditions at low engine speeds and with a swirl ratio of two, thereby providing a good correlation between the required empirical inputs to account for incylinder bulk flow and turbulence in the three models.

Two further constants are required by the newly developed Jenkin et al expression (see Table 2). A value, $d$, must be specified to represent the thickness of the region (from the cylinder surface towards the bulk core gases) where wall turbulence effects exist. $k_{l} / k$ is assumed to vary linearly across this region from the core value at $x=d$ to approximately zero in the low momentum region adjacent to the walls. This approach is justified by assuming that heat transfer between the in-cylinder gases and the cylinder walls is one-dimensional. A physical understanding of the nature of such a one-dimensional process would lead to the conclusion that it is only the component of eddy velocity normal to the cylinder wall that contributes to the net transport of enthalpy at the gaswall interfaces. Measurements made by Hall and Bracco [4] (where the radial turbulence intensity is observed to reduce as the cylinder wall is approached without peaking as in the tangential case) substantiates the $k_{t} / k$ profile

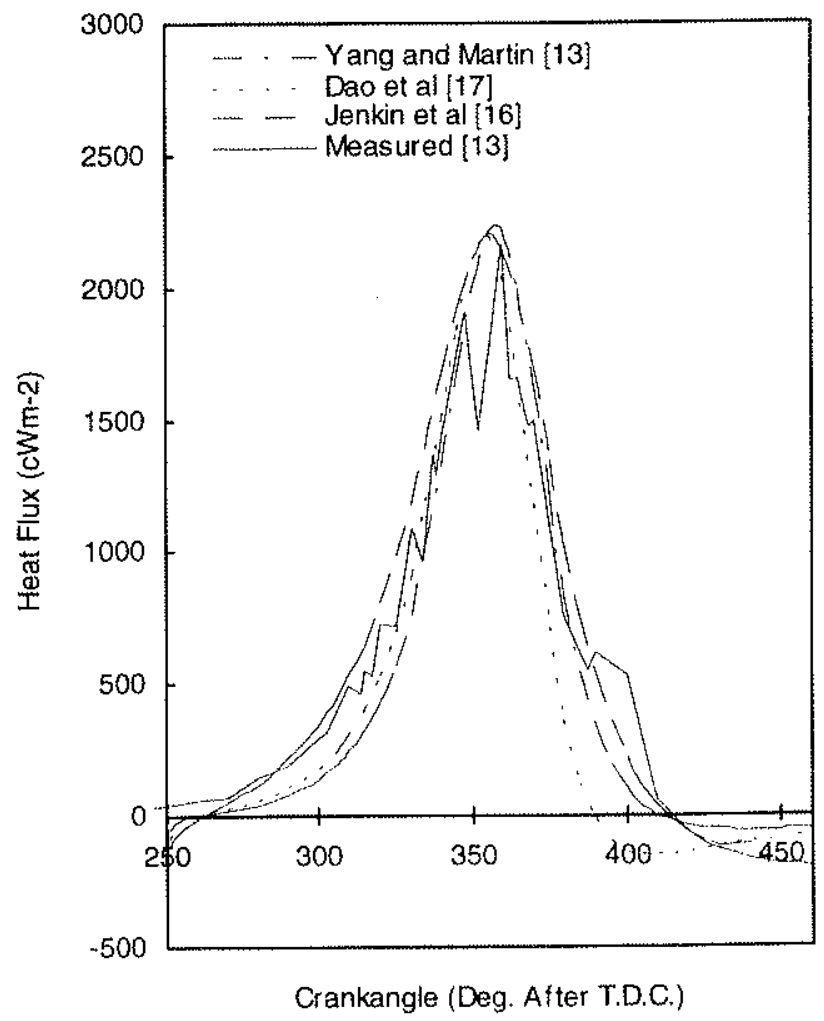

Figure 1: Heat fluxes calculated from simulated temperature profiles compared with those measured by Yang and Martin [13]. 
used. A value of $0.11 \mathrm{~cm}$ was selected for $d$ during the validation of the simulated temperature profiles in order to achieve good agreement with the measured temperature profiles. A constant to account for the thickness of the region of low momentum fluid adjacent to the cylinder surfaces is also included.

\section{RESULTS}

Figure I compares heat fluxes calculated from the predicted temperature profiles for the three $k_{t} / k$ expressions and also shows the measured results of Yang and Martin [13] obtained in a "motored" engine having a pancake shaped combustion chamber under the conditions presented in Table 1. All predicted heat fluxes show good agreement with the measured values near TDC. A direct comparison of the thermal boundary layer temperature distributions obtained with the respective $k_{t} / k$ expressions is made in Figure 2. These show differences throughout their entire development even though the heat fluxes calculated from them are very similar around TDC. This can be explained by comparisons of the values for

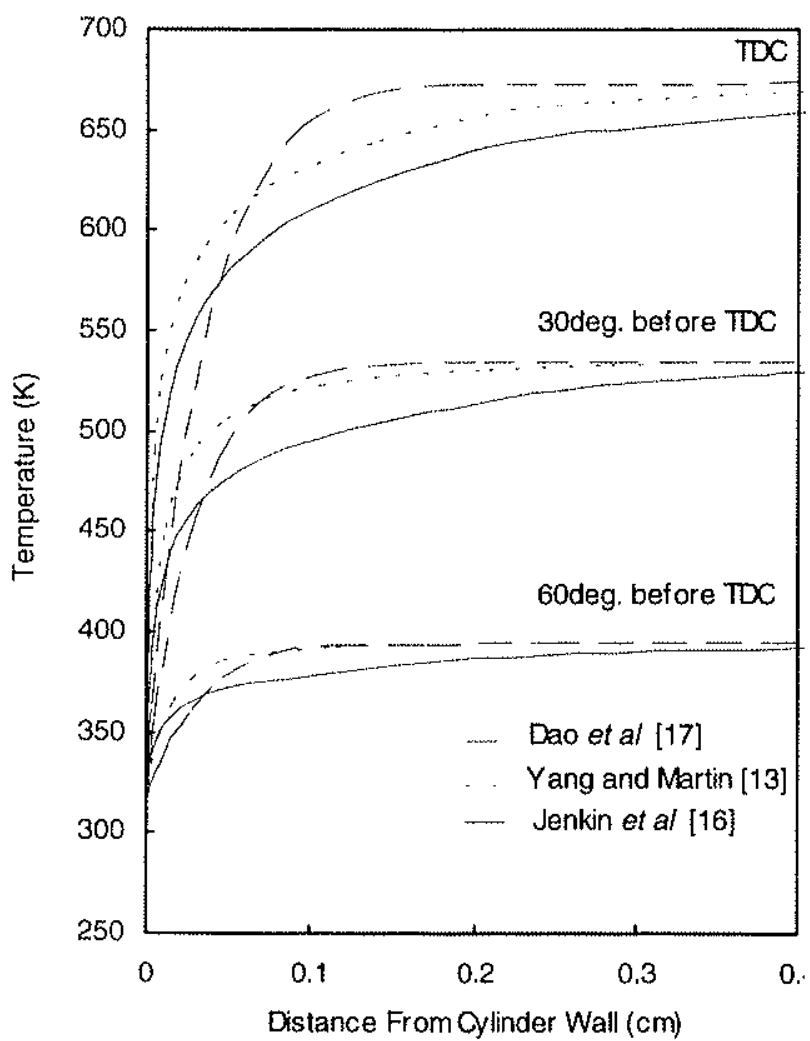

Figure 2: Simulated temperature profiles for the compression stroke of a "motored" engine employing expressions for $k_{t} / k$ developed by Dao et al [17], Yang and Martin [13] and Jenkin et al [16].

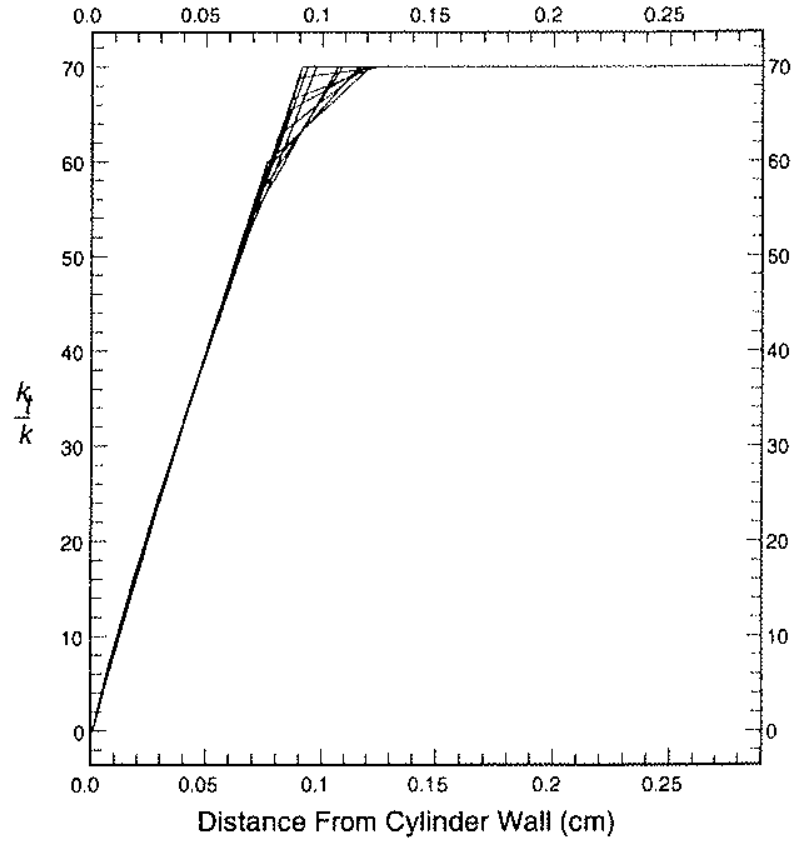

Figure 3: $k_{t} / k$ Profiles calculated from Jenkin et al [16] throughout the compression stroke of a "motored" engine.

$k_{t} / k$ provided by the different expressions. Thus, Figure 3 shows the $k_{t} / k$ profiles using the piece-wise method developed by the authors. An extremely thin region where $k_{t} / k=0$ can be observed close to the cylinder wall. This reflects the virtually laminar behaviour of the low momentum fluid adjacent to the cylinder wall. The cylinder core region has a constant $k_{l} / k$ value throughout. Between the core region and the laminar sub. layer, $k_{l} / k$ is assumed to vary linearly for the reasons outlined earlier. This type of profile for $k_{t} / k$ was suggested by Escudier [43]. The thermal boundary layer temperature profiles in Figure 2 for this particular case show the characteristics of a fully developed, turbulent thermal boundary layer adjacent to a flat plate. As a result of the reduced effective thermal conductivity near to the cylinder wall (see Figure 3), a steep temperature gradient is apparent in this region, gradually declining throughout the buffer region and into the outer reaches of the thermal boundary layer.

$k_{t} / k$ profiles calculated using the expression developed by Dao et al [17] are shown in Figure 4. They used the Reynolds Analogy concept to derive the expression

$$
\frac{K_{t}}{k}=F(\mathrm{Re})
$$

Their choice of $F(R e)$ was guided by smooth pipe flow experimental results for laminar and turbulent flows yielding the friction factors $F_{l}=64 / \mathrm{Re}$ and 


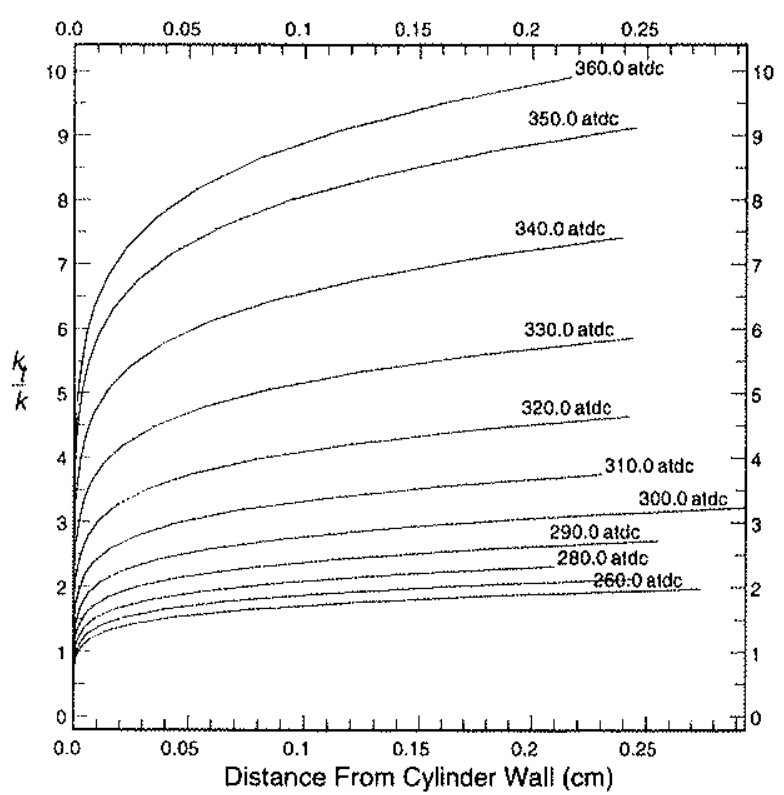

Figure 4: $k_{t} / k$ profiles calculated from Dao et al [17] throughout the compression stroke of a "motored" engine.

$F_{t}=0.316 / \mathrm{Re}^{2}$ for laminar and turbulent flows respectively such that

$$
\frac{K_{r}}{k}=\frac{F_{l}}{F_{l}}=a \operatorname{Re}^{0.75}
$$

Therefore, the ratio is strongly dependent on the Reynolds Number which was calculated by

$$
\operatorname{Re}=\frac{s \rho r \omega S R}{\mu}
$$

and is a function of the clearance distance, $s$, the density, $\rho$, and the viscosity, $\mu$, which is approximated as $\mu=\mu_{w}\left(T_{g} / T_{w}\right)^{0.77}$. The molecular viscosity increases due to heating of the cylinder gases during compression. The effects of lessening clearance height and increasing molecular viscosity are dominated by the increase in gas density, resulting in an increase in Reynolds Number as the piston ascends inferring an increase in global incylinder turbulence. This contradicts trends in global turbulence intensity which have most commonly been observed to gradually reduce during compression for simple pancake-shaped combustion chamber geometries $\{20],[21\},[30]$ with and without swirl although some researchers in high swirl situations [23] have recorded a gradual rise to a peak about $20 \mathrm{CAD}$ before TDC followed by a drop. Dao et al [17] used a $1 / 7$ th power law to express the space dependent eddy thermal conductivity, $K_{T}^{\prime}$, according to the equation:

$$
K_{\gamma}^{\prime}=K_{r}\left(\frac{x}{\delta}\right)^{1 / 2}
$$

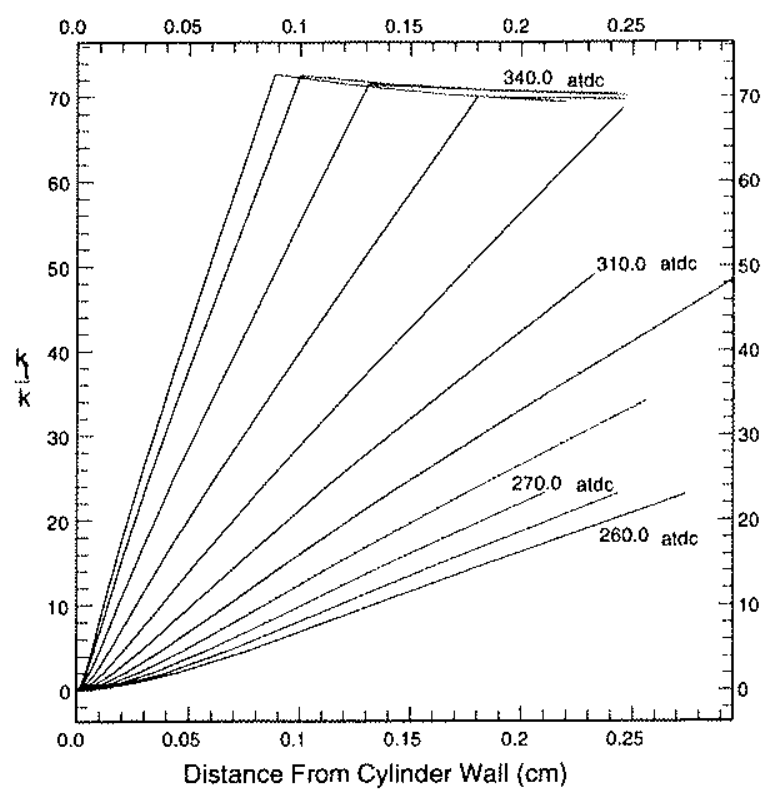

Figure 5: $k_{t} / k$ profiles calculated from Yang and Martin [13] throughout the compression stroke of a "motored" engine.

so that $K_{T}^{\prime}$ is a function of the distance from the cylinder wall, $x$ ( $\delta$ is the thermal boundary layer thickness). This is reflected in the profiles in Figure 4 , where $k_{t} / k$ can be seen to increase with distance from the cylinder wall according to a $1 / 7$ th power law profile. The TDC value of $k_{t} / k$ in the core region calculated using this expression also appears to be relatively low. As discussed earlier, a much higher value is expected in light of recent incylinder turbulence intensity [20] and integral length scale [31],[7] measurements. Also, Dao et al's expression may not be relevant to internal combustion engine work because it is based on an expression for an overall Reynolds Number and a Friction Factor as used in basic pipe flow work and the $k_{t} / k$ profile near the cylinder surfaces in engines is unlikely to approximate a $1 / 7 \mathrm{th}$ power law (a detailed discussion addressing this issue follows later).

Yang and Martin [13] have employed an algebraic expression (see EQ (3) and EQ (4)) for $k_{t} / k$ when analysing the overall gas-wall interface heat flux. This expression was used for the calculation of the $k_{t} / k$ distributions shown in Figure 5. A value for $u^{*}$ of 0.268 (Table 2) has been used in order to achieve good agreement between measured heat fluxes and those calculated from the simulated temperature profiles (Figure 1) as discussed earlier. This was necessary for the calculation of $y^{+}$in EQ (3) according to the expression:

$$
y^{+}=\frac{x u^{*}}{v}
$$




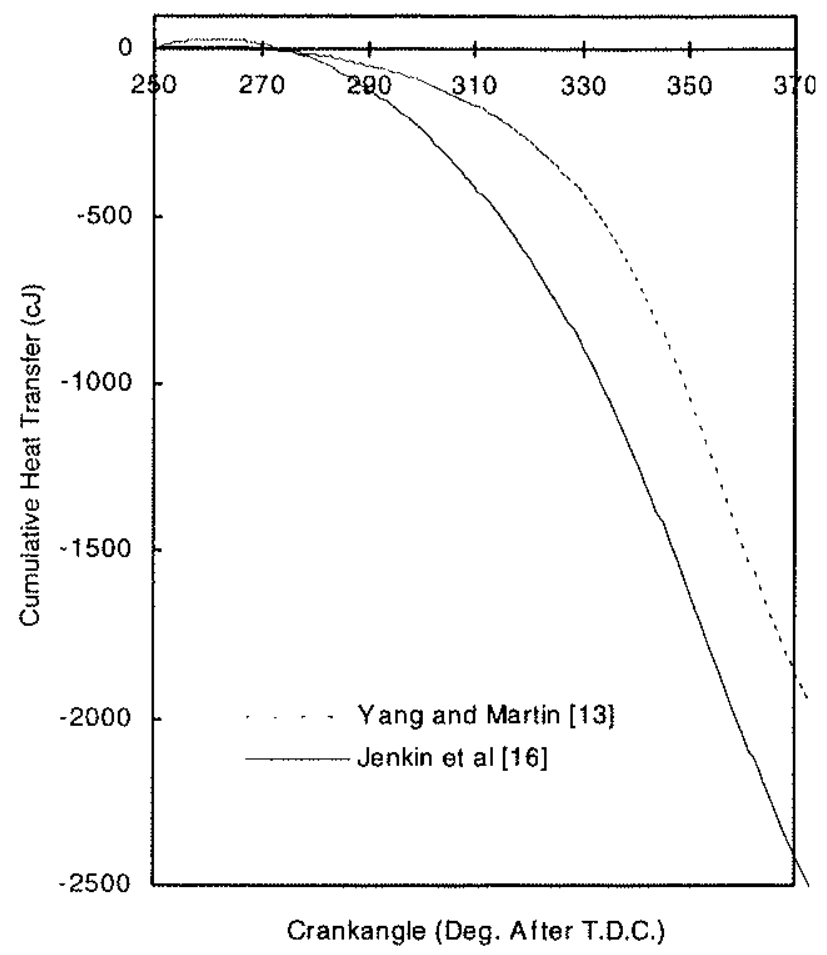

Figure 6: Cumulative heat transfer throughout the compression stroke of a "motored" engine (case where predicted TDC heat fluxes are matched to measured results).

$u^{*}$ is assumed to be constant throughout the cycle [13] and, therefore, for a given $x$, the subsequent value of $y^{+}$ is dependent on $v$. They have employed EQ (3) across the entire thickness of the thermal boundary layer in an integral solution of the Conservation of Energy Equation for gas/wall interface heat flux. The expression can be derived from Prandtl's mixing length theory. Thus, it can be shown that

$$
v_{t}=u^{*} \ell_{m}
$$

in the near wall region after assuming that the fluid shear stress is constant throughout and equal to the wall shear stress. The mixing length, $\ell_{m}$, is evaluated according to an algebraic expression. One such expression is given by van Driest [40]:

$$
\ell_{m}=\kappa y\left[1-\exp \left(\frac{-y \tau_{w}{ }^{1 / 2} \rho^{1 / 2}}{A \mu}\right)\right]
$$

where $A$ is a constant and has been empirically evaluated as 26. This employs the basic analogy that the mixing length is proportional to the distance from the cylinder wall according to the Prandtl-Kolmogorov Equation $\left(\ell_{m}=\kappa y^{\prime}\right)$ with the exponential factor accounting for the extra damping effect on the turbulence extremely close to the cylinder wall due to the viscous nature of the flow in this region [41]. Substitution of EQ (18) into EQ (17) and replacing the empirical constant $1 / A$ with $\kappa a$ yields EQ
(3). It is generally accepted that the Prandtl-Kolmogorov Equation is applicable in the region of the boundary layer close to the cylinder wall [41],[36],[35],[42] which Escudier [43] defined as $0<y / \delta \leq \lambda / \kappa$ where $\lambda=0.09$ and $\kappa=0.41$ based on analysis of much empirical data for flows adjacent to flat plates. Therefore, the outer limit of this region is given as $0.23 \delta$ which corresponds to $y^{+}=300$. He also concludes that $\mu_{1} / \mu$ is constant outside of the inner region and, therefore, the bulk value for $k_{t} / k$ has subsequently been assumed to be constant and equal to the value calculated using EQ (3) and EQ (4) at $y^{+}=300$.

Throughout compression, the gas density significantly increases. Thus, there is a net decrease in the kinematic viscosity, $v$, and this results in correspondingly larger values of $y^{+}$for a given value of $x$. This is reflected in the $k_{t} / k$ values shown in Figure 5 where the gradient of each profile in the region corresponding to the buffer zone and the bulk gases increases as compression proceeds. Again, $k_{t} / k$ values at a particular distance from the cylinder wall increase during compression and an almost constant value for $k_{t} / k$ of approximately 70 is apparent in the core region. The computed values for $k_{t} / k$ are not spatially constant throughout the core because, in this case, the turbulent eddy conductivity, $k_{t}$, is calculated

Table 3: Engine operating conditions (Lucht et al [2]).

$\begin{array}{lc}\text { Compression Ratio } & 7.0 \\ \text { Crankshaft Speed (r.p.m.) } & 600 \\ \text { Inlet Charge Temperature (K) } & 373 \\ \text { Intake Air Pressure (atm) } & 1.27\end{array}$

Table 4: Empirical input used in the calculation of TDC simulated temperature profiles.

Jenkin et al [16]:

Core turbulent eddy transport ratio.

$\left(k_{t} / k\right)$

Extent of wall effects into core

turbulence, $d(\mathrm{~mm})$

Laminar sub-layer thickness ( $\mathrm{mm}$ )

No. of boundary layer model

0.011

elements.

Dao et al [17]:

Swirl Ratio. (SR)

No. of boundary layer model

elements.

Yang and Martin [13]:

Cyclicly Averaged Global Friction

Velocity, $u^{*}(\mathrm{~m} / \mathrm{s})$

No. of boundary layer model elements. 


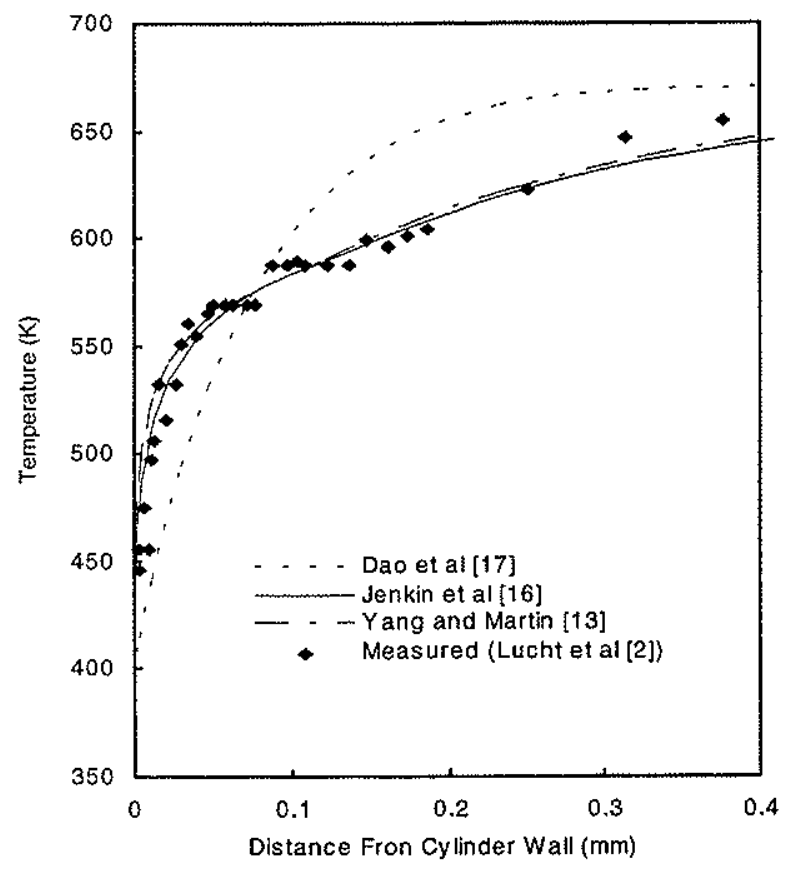

Figure 7: Simulated TDC temperature profiles compared with measurements [2].

directly and assumed to be uniform throughout the core region. Significant temperature variations occur in the core gas during compression so that the thermal conductivity, $k$, is not constant resulting in slight differences in the computed values for $k_{t} / k$. This however has very little influence on the calculated temperature profiles. These profiles show similarities with those computed using Jenkin et al's [16] expression (Figures 3 and 5). At TDC, the $k_{t} / k$ profiles are almost identical, with both sharing the characteristics of those expected in fully developed flows adjacent to flat plates [43]. However, differences are evident earlier in the compression stroke resulting in subtley different temperature profiles and considerable differences in the computed heat fluxes between IVC and $340 \mathrm{CAD}$ (Figures 1 and 2). Heat fluxes calculated when Jenkin et al's expression [16] is employed for computing $k_{t} / k$ are, at times, double those computed when Yang and Martin's expression [13] is used (Figure 1). The higher rate of heat transfer between IVC and 340 CAD results in greater cumulative heat transfer (energy loss) from the combustion chamber gases. A $25 \%$ greater cumulative energy loss at TDC is computed (Figure 6). Due to this enhanced energy loss when using Jenkin et al's expression, the cylinder core temperatures are lower However, the form of the calculated temperature profiles when using the Yang and Martin's and Jenkin et al's expressions do show some degree of conformity close to TDC (Figure 2) in contrast to those achieved using Dao et al's formula.
Calculated TDC temperature profiles employing the three expressions for $k_{t} / k$ have been compared with those measured by Lucht $e t$ al [2] in a high swirl engine having a pancake shaped combustion chamber. The operating conditions and empirical input are included in Tables 3 and 4 respectively and the calculated $k_{t} / k$ profiles are similar to those obtained previously (Figures 3 and 5). When the Dao et als' [17] expression is employed, comparison between the predicted and measured TDC temperature profiles (Figure 7) confirms its limitations in applications to engine type flows. Alternatively, the temperature profiles computed with the Yang and Martin [13] and Jenkin et al expressions show extremely good agreement when compared with the measured values (Figure 7). In contrast to the previous simulations, the empirical input was selected purely on the basis of obtaining good agreement with the measured TDC temperature profile, rather than the desire to accurately match predicted and measured heat fluxes. The predicted core temperatures closely agree for the latter two cases (Figure 7) because the predicted cumulative energy lost from the cylinder gases at TDC is almost the same for both cases (Figure 8). Differences in the predicted rate of heat loss are apparent demonstrating, once again, that the heat fluxes computed when the respective expressions for $k_{t} / k$ are employed are not entirely consistent. However, the TDC heat fluxes are within $12.5 \%$ of each other. The above results show that towards TDC, both Jenkin et al's [16] and Yang and Martin's [13] expressions for calculating $k_{t} / k$ are very



Figure 8: Cumulative heat transfer throughout the compression stroke of a "motored" engine (case where predicted TDC temperature profiles are matched To measured results). 
similar and, when employed in the engine simulation, enable the accurate prediction of TDC heat fluxes and temperature profiles. These expressions show differences in computed $k_{t} / k$ profiles early in the compression stroke and late in the expansion stroke, resulting in considerable deviations in the calculated heat fluxes and temperature profiles at these points in the cycle.

Parametric studies have shown that the distance from the wall at which the $k_{t} / k$ profiles (using both Jenkin $e t$ al's [16] and Yang and Martin's expressions [13]) level out to a constant value has very little effect on the calculated temperature profiles and heat fluxes as long as the core $k_{t} / k$ values remain relatively high. However, the predicted heat fluxes and temperature profiles are strongly dependent on the simulated laminar sub-layer behaviour and the gradient of the $k_{t} / k$ profile near the cylinder wall. If these effects are not accounted for, as is the case with Dao et al's expression [17], predicted temperature profiles are unreasonable in light of the measured ones [2] even though the heat fluxes agree with those measured by Yang and Martin [16] (Figure 1). The results presented in Figures 1 to 5 and the ensuing discussion show that, in light of current data regarding near-wall in-cylinder turbulence and temperature profiles, imprecise modelling of near-wall transport effects can still result in predicted heat fluxes showing good agreement with measured values. The simulations have shown that the calculated gas-wall interface heat flux is strongly influenced by the turbulence characteristics near to the cylinder wall. Therefore, provided that this region is reasonably well modelled, the calculated heat fluxes will show good agreement with measured ones even if the overall simulated boundary layer temperature profiles are not precisely predicted.

There is speculation as to the exact behaviour of the flow immediately adjacent to the cylinder wall. Boggs and Borman [7] and Pierce et al [6] hypothesise that turbulence must penetrate all the way to the cylinder wall based on their near wall integral length scale and turbulence measurements. Alternatively, Hall and Bracco's observations [4] in the near-wall region exhibit behaviour similar to fully developed, turbulent boundary layers adjacent to flat plates. Pierce et al [6] have speculated that this may be due to considerably different in-cylinder flows. In this study, heat fluxes and temperature profiles have been satisfactorily predicted in an engine simulation [16] when $k_{l} / k$ expressions have been employed that cater for the existence of a laminar sub-layer.

It is clear that Yang and Martin's [13] and Jenkin et al's [16] expressions both reasonably predict heat fluxes and temperature profiles around TDC. However, there is some uncertainty as to the applicability of the respective expressions early in the compression stroke. Neither expression, in light of the limited study presented here, conclusively appears to be superior. Yang and Martin's expression [13] is a boundary layer model and, theoretically, can react to the changing in-cylinder flow characteristics throughout the cycle. However, as applied here and in their study [13], the empirical constant, $u^{*}$, accounting for this does not vary and the $k_{t} / k$ profiles change only as a result of differences in the gas kinematic viscosity. This introduces inaccuracies as $u^{*}$ values computed from velocity measurements in an engine similar to that studied here [44] decline considerably during the compression stroke. If instantaneous values for $u^{*}$ were used, $k_{t} / k$ would be amplified early in the compression stroke engendering more constant $k_{t} / k$ profiles during compression. Reynolds [45] suggests that there may be insufficient time for the complete evolution of a fully developed boundary layer in the cylinders of internal combustion engines. If this is true, the boundary layer is unlikely to be fully developed especially early in the compression stroke thereby reducing the potential applicability of fully developed turbulent boundary layer theory. This, coupled with the observation that velocity [4], [5] and normal turbulence intensity [4] boundary layer thicknesses are observed to be almost constant throughout compression, has led to the tentative conclusion that the model developed by Jenkin et al most accurately accounts for the turbulent eddy transport processes in the boundary layer throughout the compression and expansion strokes of a "motored" cycle.

\section{THE LAW OF THE WALL}

The Law of the Wall has often been employed in multidimensional engine simulations to depict boundary layer temperature profiles between the cylinder wall and the nodes adjacent to it $[10],[11],[24]$. There is speculation as to the applicability of this approach to in-cylinder flows. It was not possible to include the Law of the Wall in the computer model developed here because, rather than modelling the near-wall turbulent eddy effects, it enables the calculation of the temperature distribution from an assumed dimensionless profile universally applicable to fully developed turbulent flows and requires spatial resolution of the in-cylinder near-wall velocity field in order to accurately calculate $u^{*}$. In order to assess the applicability of the wall function method to engine type near-wall flows, the temperature profiles measured by Lucht et al [2] have been expressed in dimensionless form and compared with the wall functions developed by Huh et al [11] who have modified the standard wall functions to account for pressure work effects. The dimensionless distance, $y^{+}$, is defined in $\mathrm{EQ}$ (16) and the dimensionless temperature, $T^{+}$, is defined as: 


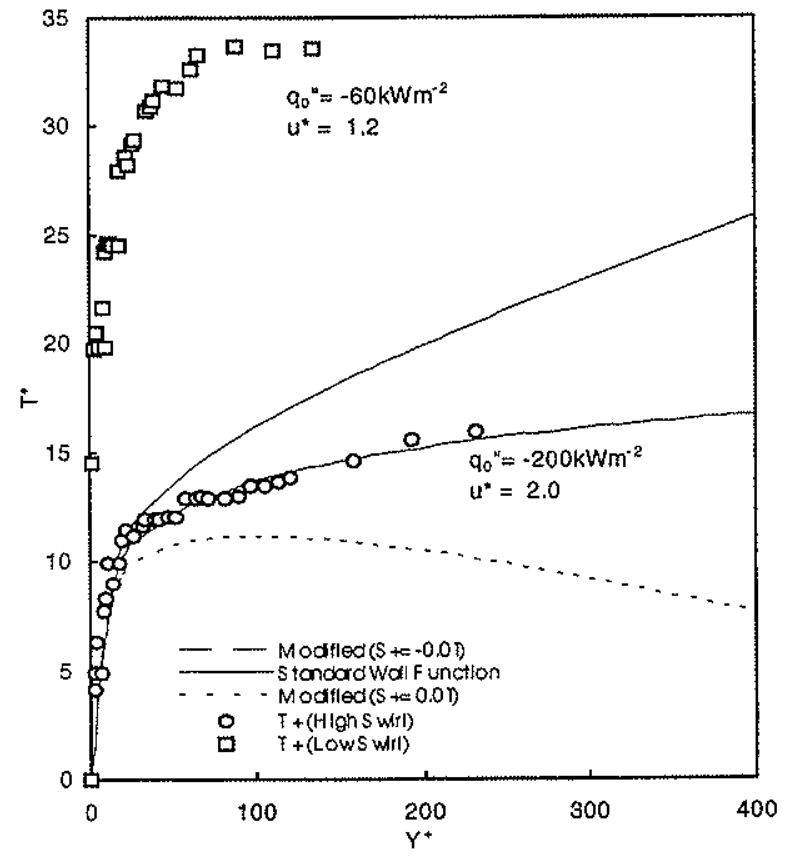

Figure 9: Measured T.D.C temperature profiles [2] in dimensionless form plotted against modified wall functions [24].

$$
T^{+}=\frac{\rho C_{p}\left(T_{0}-T\right) u^{*}}{q_{0}^{\prime \prime}}
$$

The dimensionless temperature profiles are calculated from the following wall functions [11]:

$$
\begin{aligned}
& T^{+}=\operatorname{Pr} y^{+}-0.5 \operatorname{Pr} S^{+}\left(y^{+}\right)^{2} \\
& \text { for } y^{+}<13.2
\end{aligned}
$$

and

$$
\begin{aligned}
& \begin{aligned}
T^{+} & =13.2 \mathrm{Pr}+2.195 \ln y^{+}-5.66 \\
& -S^{+}\left(87.12 \mathrm{Pr}+2.195 y^{+}-28.98\right)
\end{aligned} \\
& \text { for } y^{+}>3.2
\end{aligned}
$$

where

$$
S^{+} \stackrel{S v}{=\frac{S v}{q_{0}^{\prime \prime} u^{*}}}
$$

Figure 9 shows the resultant comparisons for both high and low swirl "motored" TDC temperature profiles. At $\mathrm{TDC}, \mathrm{dp} / \mathrm{dt}=0$. Under these conditions, the modified wall function is virtually identical to the standard wall function. Values for $q_{0}^{\prime \prime}$ were taken from the computer simulation results presented by Jenkin et al [16] in which calculated temperature profiles were closely matched to empirical results. Friction velocities were found to have a significant influence on the dimensionless temperature profiles. Suitable values for $u^{*}$ were difficult to establish because comprehensive near-wall velocity data corresponding to the conditions under which the temperature measurements were acquired was not available. Foster and Witze [5] made velocity measurements in the wall boundary layer within the engine used by Lucht et al [2] albeit with slight modifications from which $\tau_{w}$ and subsequently $u^{*}$ could be estimated. The approach used to convert the measured values into their dimensionless forms does not seem unreasonable although it is open to speculation due to the error in approximating $\tau_{w}$ because of limited velocity data extremely close to the cylinder wall.

It can be seen from Figure 9, for the high swirl case, that the dimensionless form of the measured temperature profile and the wall function method show reasonable agreement. This is not true under low swirl conditions. From this, it can be tentatively concluded that, for high swirl in-cylinder flows, the TDC temperature profiles in a "motored" engine can be approximated using wall functions. However, the accuracy is strongly dependent on the correct choice of the friction velocity, $u^{*}$. Under low swirl conditions, wall functions cannot be used to approximate boundary layer temperature distributions. This is a result of the changing nature of the in-cylinder boundary layer with bulk gas rotation as noted by Foster and Witze [5] who proposed that their measured high swirl profiles exhibited the characteristics of a turbulent boundary layer and could reasonably be approximated with a $1 / 7$ th power law. Their measured low swirl profiles were consistent with laminar boundary layers which could be approximated by a Blasius profile.

\section{THERMAL BOUNDARY LAYER DEVELOPMENT}

The thermal boundary layer model developed by the authors has been validated by comparing simulated TDC temperature profiles with measured ones and measured heat fluxes with those computed from the simulated temperature profiles throughout the cycle. In the absence of more comprehensive near wall temperature measurements throughout the compression and expansion process under "motored" conditions, it has been assumed that the computed temperature profiles at points other than top dead centre reflect the actual in-cylinder boundary layer characteristics. There is clearly some scope for error here since, in the model, it is assumed that $k_{t} / k$ in the core gas remains constant whereas it is known to vary as measured RMS turbulence velocities and length scales change during the cycle. Thus, the choice of the $k_{t} / k$ value used in the model was dictated by the desire to attain precise validation with the only known thermal boundary layer profile measurements at TDC. With a realisation of this restriction, a number of in-cylinder boundary layer phenomena can be alluded to. 
During compression and expansion, the temperature and pressure of the in-cylinder gases change due to piston work. As a result, the boundary conditions relating to the near-wall thermal boundary layer are constantly changing. Even though variations in the wall temperature are considered to be insignificant in comparison to changes in the core gas (or "bulk flow" gas) temperature, in-cylinder thermal boundary layers are transient in so much as they are constantly changing as a result of increases or decreases in the core gas temperature. At a particular instant in the cycle, the thermal boundary layer relaxes to local equilibrium given the boundary conditions at that time. Figure 10 demonstrates this for two simulations with moderate turbulence. Operating conditions and empirical input are similar to those presented in Tables 1 and 2. The solid lines show the case where the model is invoked at inlet valve closure (IVC) and the dotted lines correspond to the case where the thermal boundary layer model is invoked at $40 \mathrm{CAD}$ before IVC. In the first case, the initial conditions at IVC entail there being a straight line temperature profile throughout the combustion chamber because the boundary layer model is invoked at this point in the cycle and the initial conditions assume that the cylinder gas temperature is constant throughout. The case where the boundary layer has been modelled to develop for the $40 \mathrm{CAD}$ preceding IVC shows that a boundary layer has clearly evolved by IVC. At $270 \mathrm{CAD}$ after TDC, the boundary layer profiles are virtually identical in form with the dotted curve (corresponding to

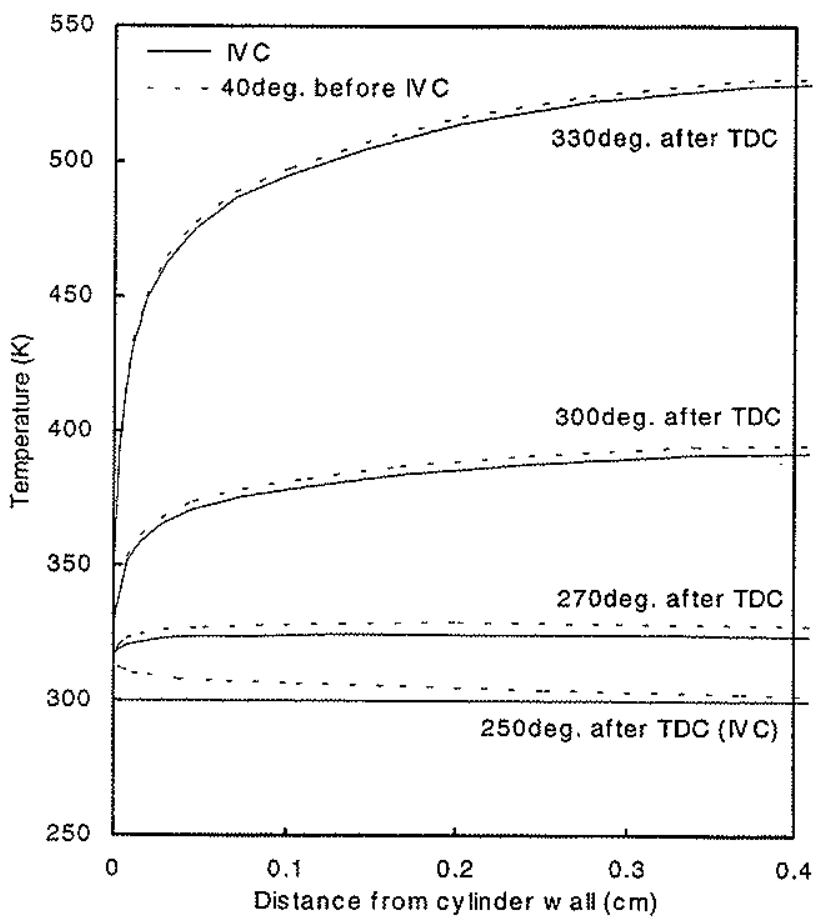

Figure 10: Simulated temperature profiles for cases where the thermal boundary layer sub-model is invoked at IVC and $40 \mathrm{CAD}$ before IVC for the compression stroke of a "motored" cycle.



Figure 11: Calculated heat fluxes compared with measurements [13].

early boundary layer development) tending towards core values 2 or $3 \mathrm{~K}$ higher. This is a result of the fractionally elevated core temperature at IVC due to heat transfer from the cylinder walls to the bulk gases prior to IVC not being accounted for in the case where the boundary layer model is invoked at IVC.

The factors influencing the profile of the thermal boundary layer at any instant in the cycle are the turbulence parameters, wall temperature, the core gas temperature and the rate of pressure work. A discussion on the relative importance of these parameters is included later. Wall temperatures and turbulence effects are constant for both cases in this study as mentioned previously. Therefore, the only factor influencing the boundary layer profiles in the cases illustrated (Figure 10) is the slight variation in core temperature. In light of the consistency of the form of the curves for both cases during compression, it can be concluded that the point of invocation of the thermal boundary layer sub-model early in compression (provided it is before IVC) appears to have virtualiy no effect on the subsequently developing boundary layer profiles. This enhances the robustness of the model. Gas-wall interface heat fluxes calculated from the corresponding simulated temperature profiles can be seen in Figure 11 where they are compared with measured heat fluxes [13] under similar operating conditions. The fluxes computed from the respective simulated profiles are virtually identical throughout the cycle as expected and show good agreement with the measured results.

A more precise analysis of the heat flux calculations between $251 \mathrm{CAD}$ (1 CAD after IVC) and $310 \mathrm{CAD}$ (see 




Figure 12: Calculated heat fluxes when the time at which the thermal boundary layer model is invoked is altered.

Figure 12) indicates that, at $251 \mathrm{CAD}$, there is a significant difference between predicted heat fluxes. They rapidly converge in the next $2 \mathrm{CAD}$ and continue to do so, although less rapidly, until they become almost identical at $305 \mathrm{CAD}$. The discrepancy observed one CAD after IVC occurs because the boundary layer model for the case represented by the solid line has only just been invoked. Initially, the in-cylinder temperature distribution is assumed to be constant right to the cylinder wall causing an extremely high simulated temperature gradient between the cylinder wall and its adjacent node. Reference to Figure 11 shows that the simulated profiles predict negative heat fluxes at this point in the cycle when the measured equivalents are positive. From this, it can be concluded that the point in the cycle at which the model is invoked does influence the calculated heat fluxes very early in the compression process and all simulations have proven to be inaccurate for this period. However, within $20 \mathrm{CAD}$ of IVC, the predicted heat fluxes rapidly converge on the measured values. The discrepancies between predicted and measured heat fluxes around IVC occur because the model does not accurately represent the near-wall flow at this point in the cycle due to the incylinder flow being disorganised, turbulence anisotropy and high turbulence intensities during the intake process and for some time after IVC [30],[32]

\section{WALL TEMPERATURE EFFECTS.}

Figure 13 illustrates computed thermal boundary layer temperature profiles during compression when the operating conditions are as shown in Table 1 apart from the cylinder wall temperature and the empirical input is as shown in Table 2 for Jenkin et al's model for $k_{f} / k$. Wall temperatures of $450 \mathrm{~K}$ (solid lines) and $350 \mathrm{~K}$ (dashed lines) have been used. Considerable differences in the thermal boundary layer temperature profiles are apparent especially early in the compression process. The high temperature walls impose a large temperature difference relative to the in-cylinder gases resulting in a rapid development of the thermal boundary layer. There is an accumulation of internal energy in the gases near the combustion chamber surfaces early in the compression stroke because of the temperature gradient (from the wall to gases) at such times. These gases are compressed from these initially high temperatures (relative to the core gas) resulting in a "bump" appearing in the boundary layer profile as compression proceeds. Lawton [12] has also demonstrated this effect during investigations of instantaneous heat transfer in engines as have Jennings and Morel [25]. The "bump" has been found to become more pronounced as the wall temperature is increased and is speculated to be one source of "knocking" in spark ignition engines [29]. This is demonstrated more clearly in Figure 14 where the wall temperature is raised to $650 \mathrm{~K}$. Conversely, when the wall temperature is low $(300 \mathrm{~K})$, the boundary layer develops in the conventional way (see Figure 13) as there is no accumulation of internal energy



Figure 13: Simulated temperature profiles during the compression stroke of a "motored" cycle when cylinder wall temperature is varied. 


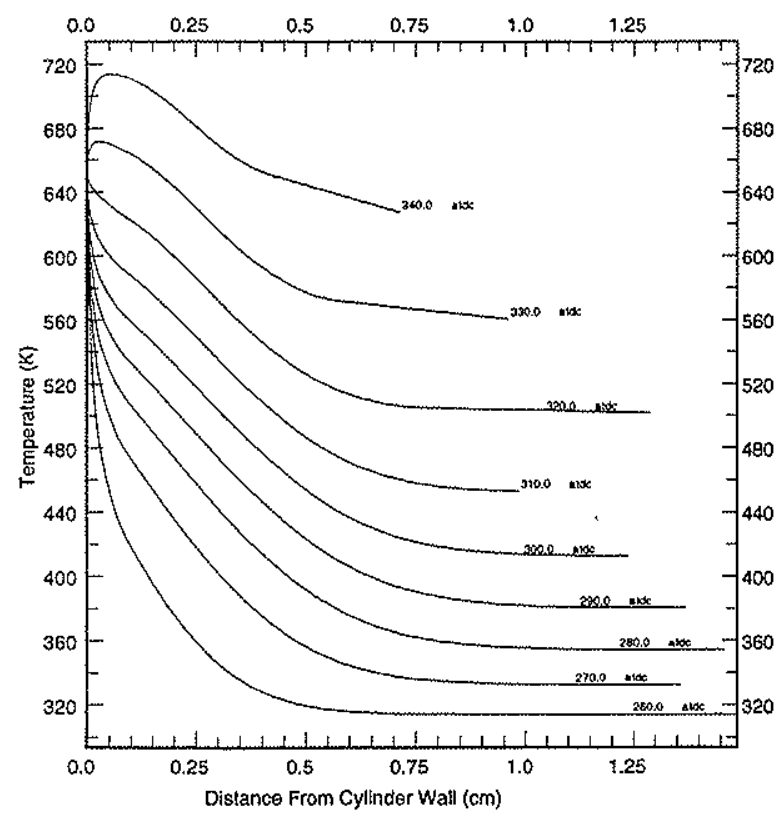

Figure 14: Calculated temperature profiles when the wall temperature is $650 \mathrm{~K}$.

in the gases adjacent to the cylinder walls early in the compression stroke because the wall and gas temperatures are similar at that time.

Figure 15 shows how differences in the two thermal boundary layer profiles affect the heat fluxes calculated from them. Increasing the wall temperature reduces the heat flux throughout compression and expansion. This trend has been noted also by Jennings and Morel [25] and Yang and Martin [26] in their computational studies of wall temperature effects. Another important feature shown on Figure 15 is the point at which heat flux passes from negative (into the cylinder gases) ${ }^{1}$ to positive (from the cylinder gases to the surroundings). During compression, heat flux is always positive for the low temperature wall case because the temperature gradient adjacent to the cylinder wall is always positive. This was confirmed by Yang and Martin's [13] measurements made at a low wall temperature (see Figure 11). Early in the compression stroke, heat flux is negative for the high temperature wall case. At 288 degrees ( 72 degrees before TDC), heat flux is zero and thereafter becomes positive. The boundary layer profiles in Figure 10 explain these phenomena. Early in the compression stroke, the temperature gradient adjacent to the cylinder wall is

'Thermodynamically, heat transfer from the cylinder contents to the walls is negative. Application of Fourier's Law to the near wall temperature gradient correctly predicts this. However, it has become conventional in many previous studies to portray the heat flux from the cylinder contents as positive in sign and this has been followed here also. negative resulting in negative heat flux. Between 280 and 300 degrees after TDC, the gradient adjacent to the cylinder wall becomes positive and, as a result, so does the heat flux. Late in the expansion stroke, a similar phenomenon occurs at the point in the cycle where heat flux changes from negative to positive for both high and low temperature walls.

\section{PISTON INDUCED PRESSURE WORK EFFECTS}

Many expressions for the calculation of heat flux have employed heat transfer coefficient type correlations of the type:

$$
q_{0}^{\prime \prime}=h\left(T_{\text {core }}-T_{\text {wall }}\right)
$$

where heat flux is a function of the driving temperature difference between the cylinder core gases and the cylinder wall. It has been noted by many researchers that when heat flux is calculated this way, a discontinuity in the heat transfer coefficient occurs late in the expansion stroke [27],[28] because, at the point when heat flux. becomes negative, the driving temperature difference $\left(T_{\text {core }}-T_{\text {wall }}\right)$ remains positive. Figure 16 plots the computed ( $\left.T_{\text {core }}-T_{\text {wall }}\right)$ temperature difference and heat flux for the high wall temperature $(450 \mathrm{~K})$ case. It can clearly be seen that, at $394 \mathrm{CAD}$, heat flux becomes negative whilst the driving temperature difference is large and positive. This phenomenon is attributable to the influence of piston induced pressure work on the gases in the thermal boundary layer and can be explained by $E Q$ (1). Ignoring the enthalpy source terms, $S_{h}$, the left hand side of this equation represents the rate of change of enthalpy. This is dependent on the divergence of the enthalpy diffusion rate (local heat flux), the local



Figure 15: Calculated heat fluxes when the wall temperatures are $450 \mathrm{~K}$ and $300 \mathrm{~K}$. 


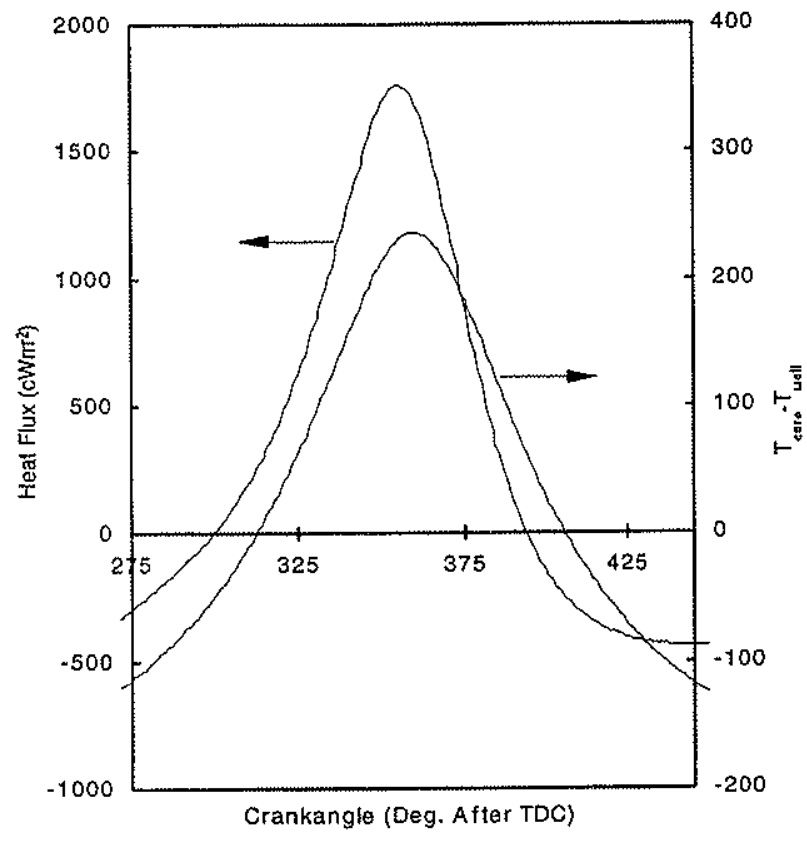

Figure 16: Calculated heat flux and $\left(T_{\text {core }}-T_{\text {wall }}\right)$ variations during compression and expansion $(450 \mathrm{~K}$ wall temperature).

temperature gradients (which vary throughout the domain) and the rate of pressure work, $d P / d t$. The latter is a time derivative and contributes evenly across the entire domain. This, coupled with the space varying diffusion of enthalpy transport, results in local accumulations or deficits of enthalpy.

Figure 17 shows computed thermal boundary layer temperature profiles around the time at which heat flux

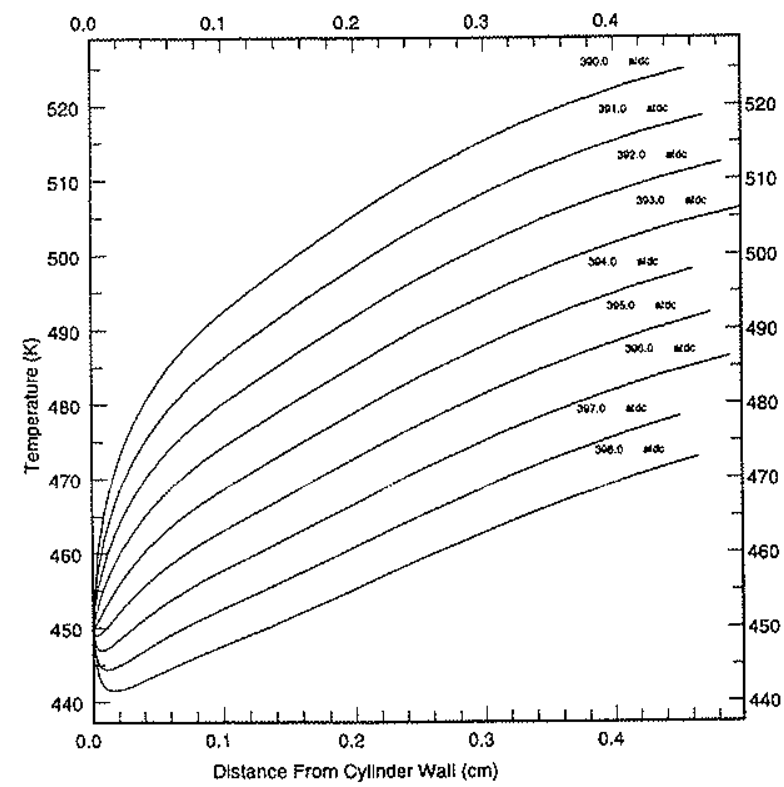

Figure 17: Calculated temperature profiles focusing on the part of the expansion stroke where heat flux passes from positive to negative in a "motored" cycle. passes from positive to negative on the expansion stroke but using a finer mesh to give better resolution of the near-wall region. At $393 \mathrm{CAD}$, the gradient adjacent to the cylinder wall is positive but, by $395 \mathrm{CAD}$, a small dip has appeared in the temperature profile near to the wall. This is as a result of a deficit of enthalpy in this region due to the combined effects of net heat loss and the negative pressure work due to gas expansion. An 's' appears in the temperature profile and, even though the core gas is significantly hotter than the cylinder wall, the temperature gradient immediately adjacent to the cylinder wall has become negative and so also therefore does the heat flux. Early in the compression stroke, the reverse effect occurs as demonstrated on Figure 18. An accumulation of internal energy occurs near to the cylinder wall as a result of the combined effects of net heat transfer and positive pressure work due to gas compression by the ascending piston. As explained earlier, a "bump" then occurs in the temperature profile at $301 \mathrm{CAD}$ promoting a positive temperature gradient even when the core gas is below the wall temperature. The effects of the "bump" influence the boundary layer temperature profile throughout the compression stroke (see Figure 13) and are especially noticeable at top dead centre where the maximum gas temperature occurs 0.25 $\mathrm{cm}$ from the cylinder wall rather than in the adiabatic core. This phenomenon is not apparent in the low temperature wall case during compression (Figure 13) as a negative temperature gradient does not initially exist. Therefore, there is no local accumulation of enthalpy as a result of the combined effects of net heat transfer and pressure work.

Figure 16 clearly shows that peak heat flux does not



Figure 18: Calculated temperature profiles focusing on the part of the compression stroke where heat flux passes from negative to positive in a "motored" cycle. 
occur at the time of maximum $\left(T_{\text {core }}-T_{\text {wall }}\right)$. Several measured cyclic heat fluxes also exhibit this behaviour $[12],[27]$. It is also attributable to the influence of piston induced pressure work on the thermal boundary layer temperature profile. Thus, towards top dead centre, the piston velocity approaches zero and so therefore does the piston induced pressure work. Consequently, compression heating of the gas adjacent to the wall becomes insignificant so that the resultant steepening of the temperature gradient due to this effect ceases allowing heat transfer alone to dominate the temperature profile. This causes a reduction in the temperature gradient adjacent to the cylinder wall and also in the gas-wall interface heat flux as the piston approaches top dead centre.

\section{CONCLUSIONS}

A newly developed, piece-wise method for calculating the effects of near wall turbulence on the transport of enthalpy (and, hence, the thermal boundary layer) in "motored" spark ignition engines has been compared to traditional methods (due to Dao et al [17] and Yang and Martin [13]). The ensuing near-wall temperature profiles that emanate from their use in a "quasi-dimensional" engine simulation program have been compared and show subtle differences throughout the compression and expansion strokes of the "motored" engine cycle. This occurs even though the corresponding calculated heat fluxes from all the methods show good agreement with measured values. From this, it can be concluded that:

i) good evaluations of gas-wall interface heat fluxes do not necessarily imply that the underlying thermal boundary layer model employed includes an accurate representation of the actual in-cylinder boundary layer turbulence phenomena (via the $k_{t} / k$ ratio employed in the transport of enthalpy equation).

ii) The algebraic expression examined based on a Reynolds No. correlation [17] does not appear to attain the required validation as the predicted temperature profiles do not compare with measured ones [2].

iii)The thermal boundary layer profiles calculated using a newly developed expression for $k_{i} / k$ (based on empirical near-wall turbulence intensity data) shows good agreement with an expression based on mixing length theory [13]. Both also correlate well with the thermal boundary layer temperature profiles measured at TDC [2]. It is speculated that the TDC $k_{f} / k$ profiles calculated with these expressions accurately account for the actual in-cylinder near-wall turbulence behaviour. However, the expressions do not show such agreement at other points in the cycle. It is tentatively suggested that the newly developed method may be most accurate because it reflects the relatively consistent momentum boundary layer thicknesses observed experimentally [4],[5].

iv) gas-wall interface heat transfer is dependent on the turbulence behaviour near to the cylinder surfaces. All the expressions used for the calculation of $k_{r} / k$ tend towards a value of zero at the wall adding weight to the hypothesis that turbulence is very low adjacent to the cylinder walls of reciprocating engines.

Our suggested approach for calculating $k_{r} / k$ accounts

for the interaction of bulk gas turbulence and the thermal boundary layer region. Its value in the bulk gas region was determined by the requirement to accurately validate the heat flux calculated from the simulated temperature profiles with that obtained experimentally by Yang and Martin [13]. Its reduction throughout the boundary layer region reflects the observations of Schlichting [36] that, for fully developed, turbulent flow adjacent to a flat plate, near wall turbulence intensities decrease in a linear manner and that $k_{f} / k$ variation is approximately proportional to the product of the turbulence intensity and characteristic eddy length scale. The latter also reduces as the cylinder wall is approached. The results of Hall and Bracco [4] and Foster and Witze [5] were used in this context to help justify the assumed $k_{f} / k$ variation near the wall. As such, the ensuing expression is not strictly a turbulence model but is based on an analysis of near wall turbulence phenomena. The bulk gas value for $k_{t} / k$ used has nevertheless been proven to be reasonable and is of the same magnitude as evaluations from Yang and Martin's [13] correlation. A simplified theoretical approach to its calculation has further enhanced its validity.

Measured TDC temperature profiles [2] expressed in dimensionless form have been further compared with wall functions modified for use in the cylinders of reciprocating engines [11]. Under high swirl conditions, there is a reasonable correlation albeit with the reservation that there is some doubt as to the accuracy of the value used for the friction velocity employed in the calculation of the dimensionless distance. It was not possible to achieve any agreement under low swirl conditions. Such observations reflect the generally accepted belief that high swirl in-cylinder, near-wall flows are fully-developed and turbulent in nature whereas low swirl flows are approximately laminar in behaviour.

Even though the thermal boundary layer validation has been achieved at TDC only on the compression stroke (due to the lack of any such additional empirical evidence), it was considered reasonable to assume that thermal boundary layer behaviour throughout the remainder of the compression and expansion strokes as predicted by the model was a relatively accurate portrayal of actual behaviour. In this context, the model indicated that compression heating and expansion cooling of the cylinder gases considerably influenced the thermal 
boundary layer profiles. In particular, the difference between the wall and gas temperature at IVC had a pronounced effect. At low wall temperatures, conventional temperature profiles in the boundary layer ensue but, at high wall temperatures, a "bump" occurs in these profiles as compression proceeds due to local accumulations of enthalpy as a result of the combined effects of the heat transfer and pressure work. It has been speculated that this may be one cause of auto-ignition in the "endgas" region of spark ignition engines [29]. The influence of pressure work effects on the near wall temperature profiles have been shown to be the cause of the phase shift between gas-wall interface heat fluxes and $\left(T_{\text {CORE }}-T_{\text {WALL }}\right)$ that have been noted by many researchers [28],[22].

The near-wall temperature profiles are dependent on the wall and core gas temperatures, the turbulent eddy transport effects and the rate of pressure work but are independent of the temperature profile history. This indicates that, at a particular instant in the cycle, the thermal boundary layer is "relaxed" to its fully developed condition and varies as a consequence of changing core temperatures and rates of pressure work.

\section{SYMBOLS}

a dimensionless constant

A dimensionless constant

b dimensionless constant

c clearance space

$C_{f} \quad$ coefficient of friction

$C_{p} \quad$ specific heat capacity at constant pressure

$C R \quad$ compression ratio

$h \quad$ specific enthalpy

$k$ molecular thermal conductivity or turbulent

kinetic energy

$k_{t} \quad$ turbulent eddy thermal conductivity

$K_{T} \quad$ turbulent eddy-thermal conductivity in "bulk" gases (used by Dao et al 171)

$K_{T}^{\prime} \quad$ space-dependent eddy-thermal conductivity

$=k_{t}$ (used by Dao et al 17])

$l \quad$ turbulence length scale

$\ell_{m} \quad$ Prandtl's mixing length

$n$ crankshaft speed

$P \quad$ cylinder pressure

$P_{a} \quad$ standard atmospheric pressure

$P_{I} \quad$ cylinder pressure at end of intake stroke

Pr molecular Prandtl number

$\mathrm{Pr}_{t} \quad$ turbulent Prandtl number

$q_{0}^{\prime \prime} \quad$ gas-wall interface heat flux

$r \quad$ radius measured from cylinder centre

Re Reynolds number

$s \quad$ instantaneous clearence height
$S \quad-\frac{d P}{d t}$

$S_{h} \quad$ enthalpy source terms

$S R$ swirl ratio (swirl angular velocity/ $\omega$ )

$t$ time

$T \quad$ gas temperature

$T_{0} \quad$ wall temperature

$T_{g} \quad$ average bulk gas temperature

$T_{I} \quad T_{g}$ at end of the intake stroke

$T_{w} \quad$ wall temperature

$u^{\prime} \quad$ turbulence intensity

$u^{*} \quad$ friction velocity $\left(\tau_{w} / \rho\right)^{1 / 2}$

$v \quad$ kinematic viscosity

$x \quad$ distance from the cylinder wall

$y \quad$ normalised distance from wall

$y^{+} \quad$ dimensionless distance

$\delta$ thermal boundary layer thickness

$\varepsilon \quad$ eddy diffusivity

$\kappa$ von-Karman constant (0.41)

$\mu \quad$ viscosity

$\mu_{t} \quad$ turbulent eddy viscosity

$v$, turbulent eddy kinematic viscosity

$\rho \quad$ gas density

$\tau_{w} \quad$ shear stress at the cylinder wall

$v_{w} \quad$ initial gas kinematic viscosity at the wall temperature

$\omega$ engine flywheel angular velocity

$\omega_{s} \quad$ swirl angular velocity $\left(\omega_{s}=S R \times \pi n / 30\right)$

\section{ABBREVIATIONS}

IVC inlet valve closure

CAD crank angle degrees

TDC top dead centre

\section{REFERENCES}

[1] Lydford-Pike, E.J. and Heywood, J.B., "Thermal Boundary Layer Thicknesses in the Cylinder of a Spark Ignition Engine," Int. Journ. Heat Mass Trans., Vol27, No10, pp1873-1878, 1984.

[2] Lucht, R.P., Dunn-Rankin, D., Walter, T,. Dreier, T and. Bopp, S. C, "Heat Transfer in Engines: Comparison of CARS Thermal Boundary Layer and Heat Flux Measurements," Paper No 910722, SAE, 1991.

[3] Yamada, S., Paulsen, H. and Farrell, P., "Heat Transfer Measurements in a Motored Engine," Paper No 890319, S.A.E., 1989.

[4] Hall, M.J. and Bracco, F.V., "Cycle Resolved Velocity and Turbulence Measurements Near the 
Cylinder Wall of a Firing S.I. Engine," Paper No 861530, S.A.E., 1986.

[5] Foster, D.E. and Witze, P.O., "Velocity Measurements in the Wall Boundary Layer of a Spark Ignited Research Engine," Paper No 872105, S.A.E., 1987.

[6] Pierce, P.H., Ghandhi, J.B. and Martin, J.K., "Near" Wall Velocity Characteristics in Valved and Ported Motored Engines," Paper No 920152, S.A.E., 1992.

[7] Boggs, D. and Borman, G., "Calculation of Heat Flux Integral Length Scales from Spatially-Resolved Surface Temperature Measurements in an Engine," Paper No. 910721, S.A.E, 1991.

[8] Jennings, M.J. and Morel, T., "An Improved Near Wall Heat Transfer Model for Multi-Dimensional Engine Flow Calculations," Paper No 900251, SAE 1990.

[9] Jennings, M.J. and Morel, T., "Modelling of Turbulent Heat Transfer with Application to I.C Engines," Paper No 872104, S.A.E., 1987.

[10]Reitz, R.D., "Assessment of Wall Heat Transfer Models for Premixed-Charge Engine Combustion Computations," Paper No 910267, S.A.E., 1991.

[11] Huh, K.Y., Chang, I. and Martin, J.K., "A Comparison of Boundary Layer Treatments for Heat Transfer in I.C Engines," Paper No 900252, S.A.E., 1990.

[12]Lawton, B., "Effect of Compression and Expansion on Instantaneous Heat Transfer in Reciprocating Internal Combustion Engines," Proc. Instn. Mech. Engrs., Vol.201, No.A3, 1987.

[13] Yang, J. and Martin, J.K., "Approximate SolutionOne-Dimensional Energy Equation for Transient, Compressible, Low Mach Number Turbulent Boundary Layer Flows," Journal of Heat and Mass Transfer, Vol. 111, pp. 619-624, 1989.

[14] Puzinauskas, P. and Burgnakke, C., "Evaluation of Unsteady Heat Transfer Model for Spark Ignition Engines," Paper No 910298, S.A.E., 1991.

[15]Chen, C. and Veshagh, A., "A One-Dimensional Model for In-Cylinder Heat Convection Based on Boundary Layer Theory," S.A.E. Technical Paper Series, pp. 1-17, 1992.

[16] Jenkin, R.J., James, E.H. and Malalasekera, W.M., "Modelling Near Wall Temperature Gradients in 'Motored' Spark Ignition Engines," Paper No. 960060, S.A.E., 1996.

[17]Dao, K., Uyehara, O.A. and Myres, P.S., "Heat Transfer Rates at Gas-Wall Interfaces in Motored Piston Engine," Paper No. 760632, S.A.E., 1973.

[18] Mellor, G.L., Proc. Symp. Internal Flow, Pennsylvania State University, Washington, D.C., 1968.

[19] Reichardt, H., Ann Angew. Math. Mech., Vol. 31, p.7, 1951.
[20]Hall, M.J. and Bracco, F.V., "A Study of Velocities and Turbulence Intensities Measured in Firing and Motored Engines," Paper No.870453, S.A.E., 1987.

[21] Arcoumanis, C., Bicen, A.F. and Whitelaw, J.H., "Effect of Inlet Parameters on the Flow Characteristics in a Four-Stroke Model Engine," Paper No. 820750, S.A.E, 1982.

[22] Heywood, J.B., Internal Combustion Engine Fundamentals, McGraw-Hill, New York, 1988.

[23] Ikegami, M., Shioji, M., Wei, D.Y. and Sugiura, M., "In-Cylinder Measurement of Turbulence by Laser Monodyne Principle," International Symposium on Diagnostics and Modelling of Combustion in Reciprocating Engines," Tokyo, September 1985.

[24] Fuh, K. Kim, Y.K. and Min, K., "Multidimensional Cycle Simulation of Flow Field, Combustion and Heat Transfer in a Spark Ignition Engine," Paper No. 920588, S.A.E., 1992.

[25] Jennings, M.J. and Morel, T., "A Computational Study of Wall Temperature Effects on Engine Heat Transfer," Paper No. 910459, S.A.E., 1991.

[26] Yang, J. and Martin, J.K., "Predictions of the Effects of High Temperature Walls, Combustion, and Knock on Heat Transfer in Engine-Type Flows," Paper No. 900690, S.A.E., 1990.

[27] Kornhauser, A.A. and Smith, J.L., "Application of a Complex Nusselt Number During Compression and Expansion," Vol. 116, pp. 536-542, Trans. of A.S.M.E., 1994.

[28] Hassan, H., "Unsteady Heat Transfer in a Motored Internal Combustion Engine," Ph.D. Thesis, Lough. Univ. Tech., 1968.

[29] James, E.H., Jenkin, R.J. and Malalasekera, W.M., "Modelling Near Wall Temperature Distributions in "Motored" Spark Ignition Engines and Their Implications For Knock," submitted for publication in "Comb. and Flame."

[30] Hill, P.G. and Zhang, D, "The Effects of Swirl and Tumble on Combustion in Spark-Ignition Engines," Vol. 20, pp.373-429, Prog. Energy Combust. Sci., 1994.

[31] Fraser, R.A. and Bracco, F.V., "Cycle-Resolved LDV Integral Length Scale Measurements in an I.C. Engine," S.A.E. Paper No. 880381, 1988.

[32] Belaire, C.B., Davis, G.C., Kent, J.C. and Tabaczynski, R.J., "Combustion Chamber Effects on Burn Rates in a High Swirl Spark Ignition Engine," S.A.E. Paper No. 830335, 1983.

[33] Bopp, S., Vafidis, C, and Whitelaw, J.H., "The Effect of Engine Speed on the TDC Flow field in a Motored Reciprocating Engine," S.A.E. Paper No. 860023, 1986.

[34] Heywood, J.B., "Fluid Motion Within the Cylinder of Internal Combustion Engines- The 1986 Freeman Scholar Lecture," Journ. of Fluids Eng., Vol. 109/3, 1987. 
[35] Launder,B.E. and Spalding,D.B., Lectures in Mathematical Models of Turbulence, Academic Press, London, 1972.

[36] Schlichting, H., Boundary Layer Theory, McGrawHill, New York, 1960.

[37] Trigui, N., Kent, J.C., Guezennec, Y. and W. C. Choi, "Characterisation of Intake Generated Fluid Flow Fields in IC Engines Using 3-D Particle Tracking Velocimetry (3-D PTV)," S.A.E Paper No. 940279, 1994.

[38] Arcoumanis, A.F., Bicen, A.F. and Whitelaw, J.H., "Effect of Inlet Parameters on the Flow Characteristics in a Four-Stroke Model Engine," S.A.E Paper No. 820750, 1982.

[39] Vafidis, C., "Influence of Induction Swirl and Piston Configuration on Air Flow in a Four-Stroke Model Engine," Proc. Instn. Mech. Engrs., Vol. 198C, No.8, 1984.

[40] van Driest, E.R., "On Turbulent Flow Near a Wall," J. A'eronaut. Sci., 23, 1007, 1956.

[41] Young, A.D., Boundary Layers, BSP Professional Books, London, 1989.

[42] Patankar S.V. and Spalding, D.B, Heat and Mass Transfer in Boundary Layers, Intertext Books, London, 1970.

[43] Escudier, M.P., "The Distribution of Mixing Length in Turbulent Flows Near Walls," Imperial College Mech. Eng. Dept. Rep TWF/TN/1.

[44] Yang, J., Pierce, P., Martin, J.K., and Foster, D.E., "Heat Transfer Predictions and Experiments in a Motored Engine," S.A.E. Paper No. 881314, 1988.

[45] Reynolds, W.C., "Modelling of Fluid Motion in Engines, an Introductory Overview," from Combustion Modelling in Reciprocating Engines, Plenum Press, New York, 1980.

[46] Kays, W.M., " Turbulent Prandtl Number - Where Are We?" ASME J. Heat Transfer, Vol. 116, p.284, 1994. 